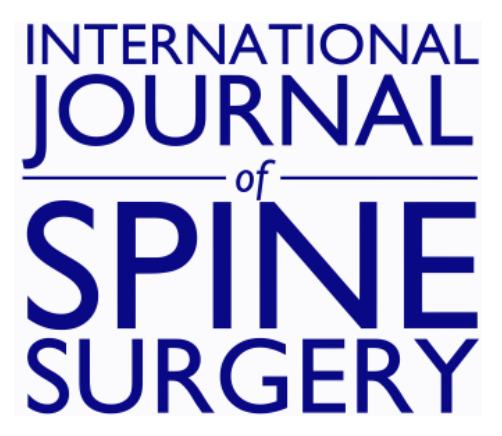

\title{
Review of Current Evidence for Minimally Invasive Posterior Sacroiliac Joint Fusion
}

David W. Lee, Denis G. Patterson and Dawood Sayed

Int J Spine Surg 2021, 15 (3) 514-524

doi: https://doi.org/10.14444/8073

http://ijssurgery.com/content/15/3/514

This information is current as of April 26, 2023.

Email Alerts Receive free email-alerts when new articles cite this article. Sign up at:

http://ijssurgery.com/alerts

The International Journal of Spine Surgery

2397 Waterbury Circle, Suite 1,

Aurora, IL 60504, Phone: +1-630-375-1432 


\title{
Review of Current Evidence for Minimally Invasive Posterior Sacroiliac Joint Fusion
}

\author{
DAVID W. LEE, MD ${ }^{1}$ DENIS G. PATTERSON, DO ${ }^{2}$ DAWOOD SAYED, MD $^{3}$ \\ ${ }^{1}$ Fullerton Orthopedic Surgery Medical Group, Fullerton, California ${ }^{2}$ Nevada Advanced Pain Specialists, Reno, Nevada ${ }^{3}$ Department of Anesthesiology, University \\ of Kansas Medical Center, Kansas City, Kansas
}

\begin{abstract}
The sacroiliac joint (SIJ) is a large, irregularly shaped, serpentine joint structure bordered anteriorly and posteriorly by the sacroiliac ligaments. With increased recognition of the SIJ as a pain source, treatments have been historically nonsurgical in nature. Common treatments include bracing, medications, activity modification, manual therapy, chiropractic manipulation, physical therapy, and intra-articular SIJ injections. Surgical stabilization and/or fusion of the SIJ may be considered when a patient has persistent moderate to severe pain, functional impairment, and failed conservative management. Surgical stabilization and fusion has traditionally been by way of the transiliac approach. More recent SIJ fusion systems have proposed not only a posterior approach but one that stabilizes the joint space by placing an allograft within the SIJ. Anatomically, a posterior approach is able to avoid neurovascular structures that otherwise are encountered with the transiliac approach and may be performed percutaneously. Preliminary evidence reports consistent pain reduction with minimal complications. This paper is purposed to detail the present evidence of minimally invasive posterior SIJ fusion, as well as highlight the need for further research moving forward.
\end{abstract}

New Technology

\section{INTRODUCTION}

Chronic pain is an issue that many Americans suffer with on a daily basis. The Centers for Disease Control and Prevention estimate that 50 million adult Americans suffer from chronic pain. This equates to $20 \%$ of the American adult population. ${ }^{1}$ Chronic pain contributes to an estimated $\$ 560$ billion each year in direct medical costs, lost productivity, and disability programs. ${ }^{2}$ Low back pain is the most common cause for chronic pain, accounting for $27 \%$ of those who suffer from pain. Lower back pain is the number-one musculoskeletal disorder for disability worldwide. ${ }^{3}$

The sacroiliac iliac joint (SIJ), in a number of series, has been estimated to contribute $10 \%-38 \%$ of cases of low back pain. ${ }^{4-6}$ The SIJ is a large, irregularly shaped, serpentine joint structure bordered anteriorly and posteriorly by the sacroiliac ligaments. The joint itself is about two-thirds synovial and one-third ligamentous, with the synovial portion extending anteroinferiorly and reinforced at its posterosuperior aspect by syndesmotic ligament The form of the SIJ begets its function - it is intended for stability, with a sacral concave depression interlocking with a corresponding iliac osseous ridge. ${ }^{7}$ This construct is further reinforced extra-articularly by the sacrospinous and sacrotuberous ligaments. The SIJ complex is part of the kinetic chain connecting the spine and lower extremities and may be a primary or secondary pain generator depending on the clinical scenario.

Surgical stabilization and/or fusion of the SIJ may be considered when a patient has persistent moderate to severe pain or functional impairment, and has been proposed as an option when a patient has failed intensive nonoperative care. Surgical stabilization and/or fusion can be performed by 3 approaches: (1) a lateral approach, (2) a posterior approach, and (3) a posterior oblique approach. The medical literature has shown that minimally invasive surgical treatment for the SIJ can improve pain and increase function. ${ }^{8-18}$ It should be noted that the current medical literature supports the lateral approach, and that presently there are limited studies that support the posterior and posterior lateral oblique approach.

\section{Posterior and Posterior Oblique Approach}

Recent minimally invasive surgical techniques have been described to stabilize the SIJ from a posterior and posterior oblique approach. These surgical techniques stabilize the SIJ by either placing 
1-3 surgical screws across the joint utilizing a posterior-oblique trajectory, or by placing 1-2 percutaneous cortical allografts posteriorly within the joint. These approaches are briefly described below.

\section{Surgical Screw Fixation}

The fluoroscope is positioned in a sacral outlet view to approximate the posterior sacral iliac spine between the S1 and S2 foramina where the implants will best be accommodated. The approach is lateral to the posterior sacral iliac spine and pointed toward the sacral promontory. A pedicle access kit (PAK) needle is advanced through the ilium, across the SIJ, and into the sacrum. A guidewire is replaced with the PAK needle through which drilling is performed. A threaded implant is then advanced through the prepared channel across the SIJ until the implant head is flush with the ilium. The steps are repeated to place up to 3 implants at the surgeon's discretion.

\section{Percutaneous Graft Placement(s)}

The fluoroscope is rotated in a medial to lateral oblique orientation $\left(15^{\circ}-20^{\circ}\right)$ until the posterior and anterior SIJ lines become superimposed. A Steinman pin (or pins) is then placed into the SIJ with the choice of 1 or 2 allografts placement. The SIJ is decorticated by using a joint decorticator and/or surgical drill through the guide retraction tube. Demineralized bone matrix (DBM) and the cortical allograft(s) are then placed within the SIJ.

\section{MATERIAL AND METHODS}

The authors conducted PubMed, OVID, and Google searches for "minimally invasive posterior sacroiliac joint fusion," "percutaneous sacroiliac joint fusion," and "sacroiliac joint allograft implantation." Searches included dates from 2010 to 2020. The abstracts or publications were excluded if they focused on open SIJ fusion treatment as opposed to minimally invasive fusion, or involved the transiliac SIJ fusion systems as opposed to the posterior approach.

There were 10 minimally invasive posterior sacroiliac fusion studies drawn from the original search (Table). These included a prospective observational study, in addition to both prospective and retrospective case series. Of particular note is that non-peer-reviewed case series were included in this systematic review; these include those by Patterson et al, ${ }^{23}$ Mann et al, ${ }^{24}$ Pyles et al, ${ }^{25}$ Pyles, ${ }^{26}$ and Kim et al. ${ }^{27}$ The authors recognize the weakness involved with these data, but included them due to the overall lack of peer-reviewed studies covering both minimally invasive posterior sacroiliac fusion and posteriorly implant allograft systems. The 10 included studies had a variety of reported outcome measures. Four of the studies utilized posterior sacroiliac joint fusion systems that involved posterior oblique fixation across the joint (Figures 1 and 2). The remaining 6 studies included involved novel allograft implant systems within the joint to achieve sacroiliac stabilization (Figure 3).

The authors were not able to conduct a metaanalysis of the data sets due to the following limitations: (1) the raw data from each include case series were not always included nor were they available upon request, (2) different outcomes measures were utilized, and (3) there was a lack of consistent follow-up timing. In the majority of the included studies, visual analog scale (VAS) or numerical rating scale (NRS) were used to track data; however, the actual values were not always included in the publication. The "percentage pain reduction" or "percentage pain improvement" was included in the majority of the studies (Figure 4). And in cases where these data were not provided, the value was calculated utilizing the difference between preoperative and postoperative VAS or NRS scores (Figure 5). The study by Wise and Dall $^{20}$ was excluded from the percentage calculation because the authors did not include the actual data in the publication.

The purpose of this review is to summarize the clinical outcome studies related to the posterior and posterior oblique minimally invasive SIJ fusion approaches. A review of this information should familiarize clinicians with the various implant types and the evidence presently available.

\section{RESULTS}

\section{Minimally Invasive Posterior Sacroiliac Fusion Evidence}

The retrospective series by Endres et al ${ }^{19}$ includes 19 patients with a hollow threaded fusion cage (DIANA cage, Signus, Alzenau, Germany). Intraoperative blood loss was less than $150 \mathrm{~mL}$ in all cases. The average length of stay was 7.3 days. Mean VAS SIJ pain scores decreased from 8.5 at baseline to 6 at final follow-up (mean, 13.2 months). 


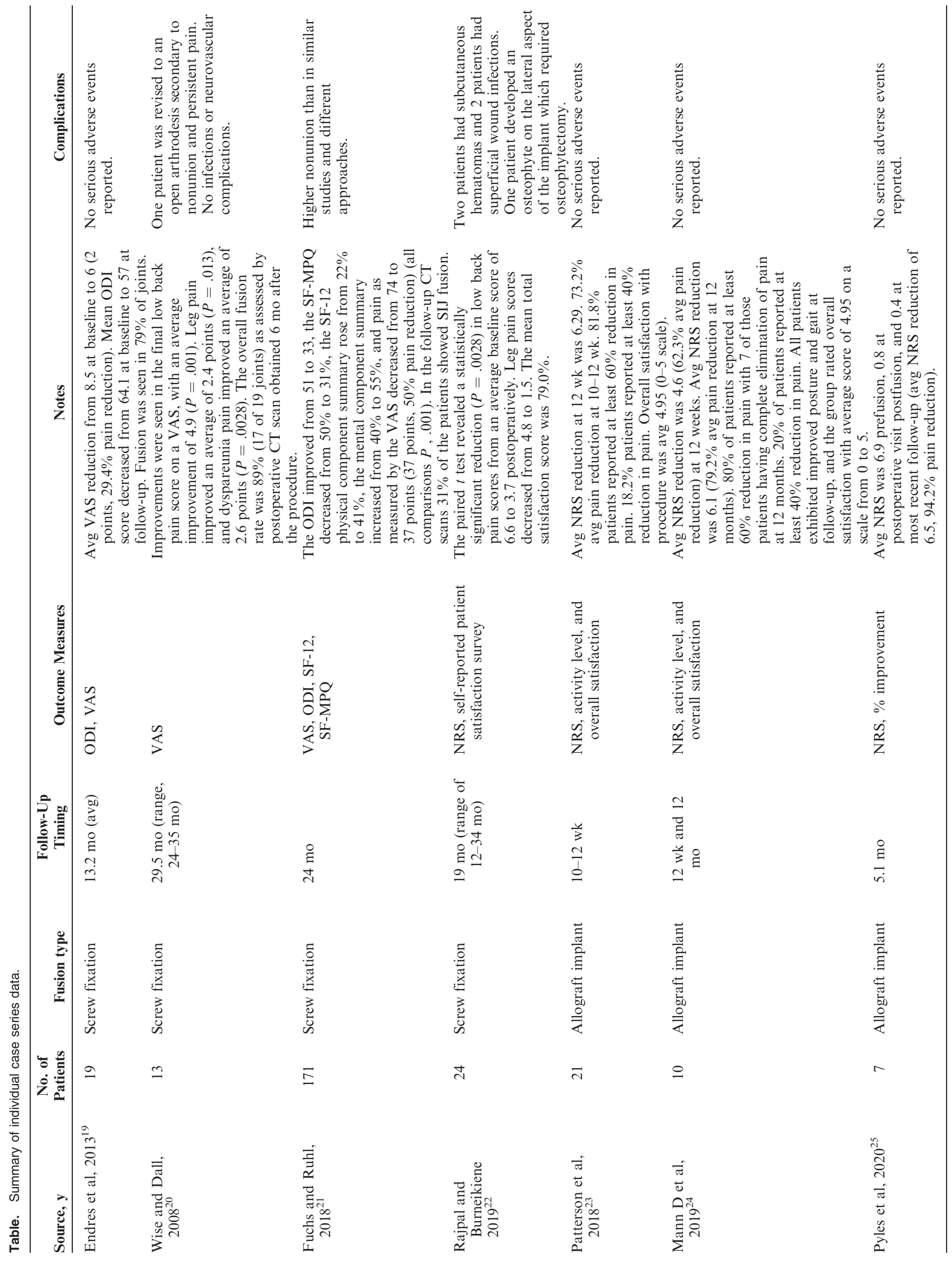


Lee et al.

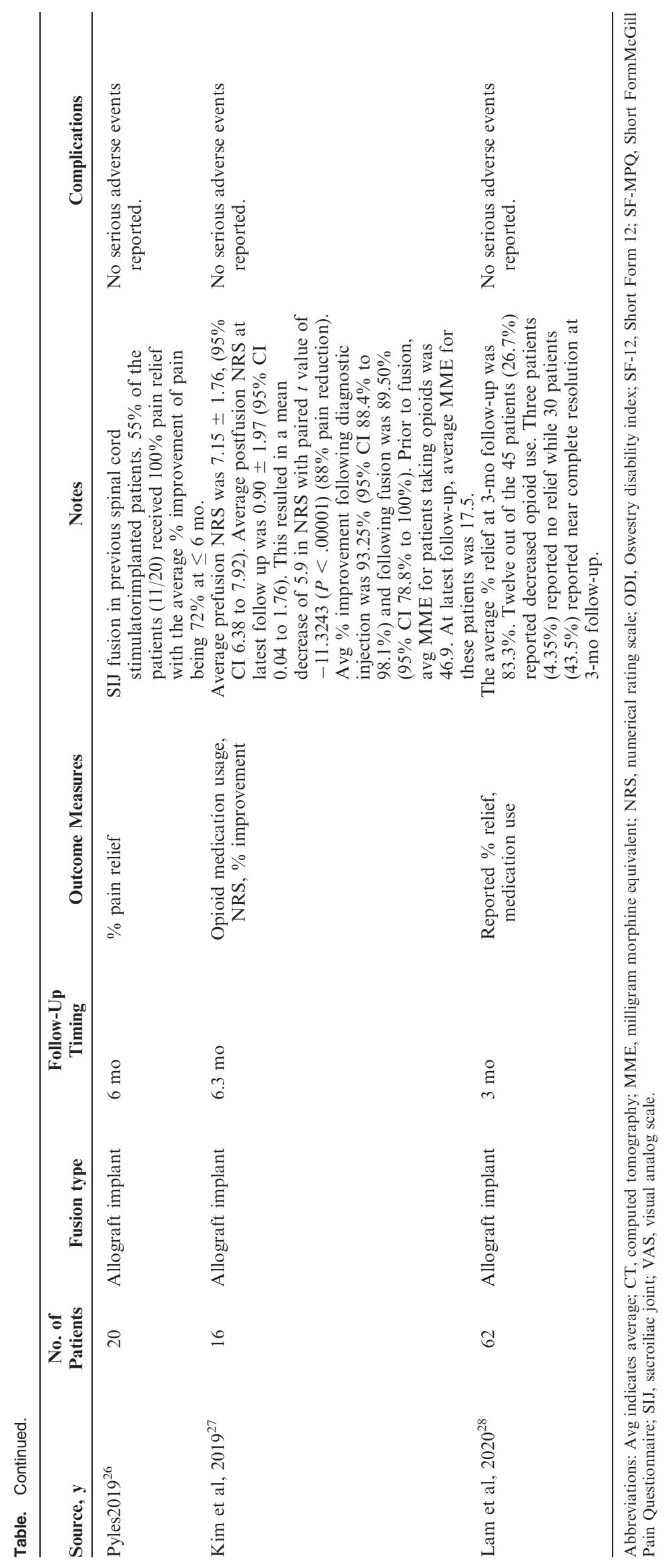




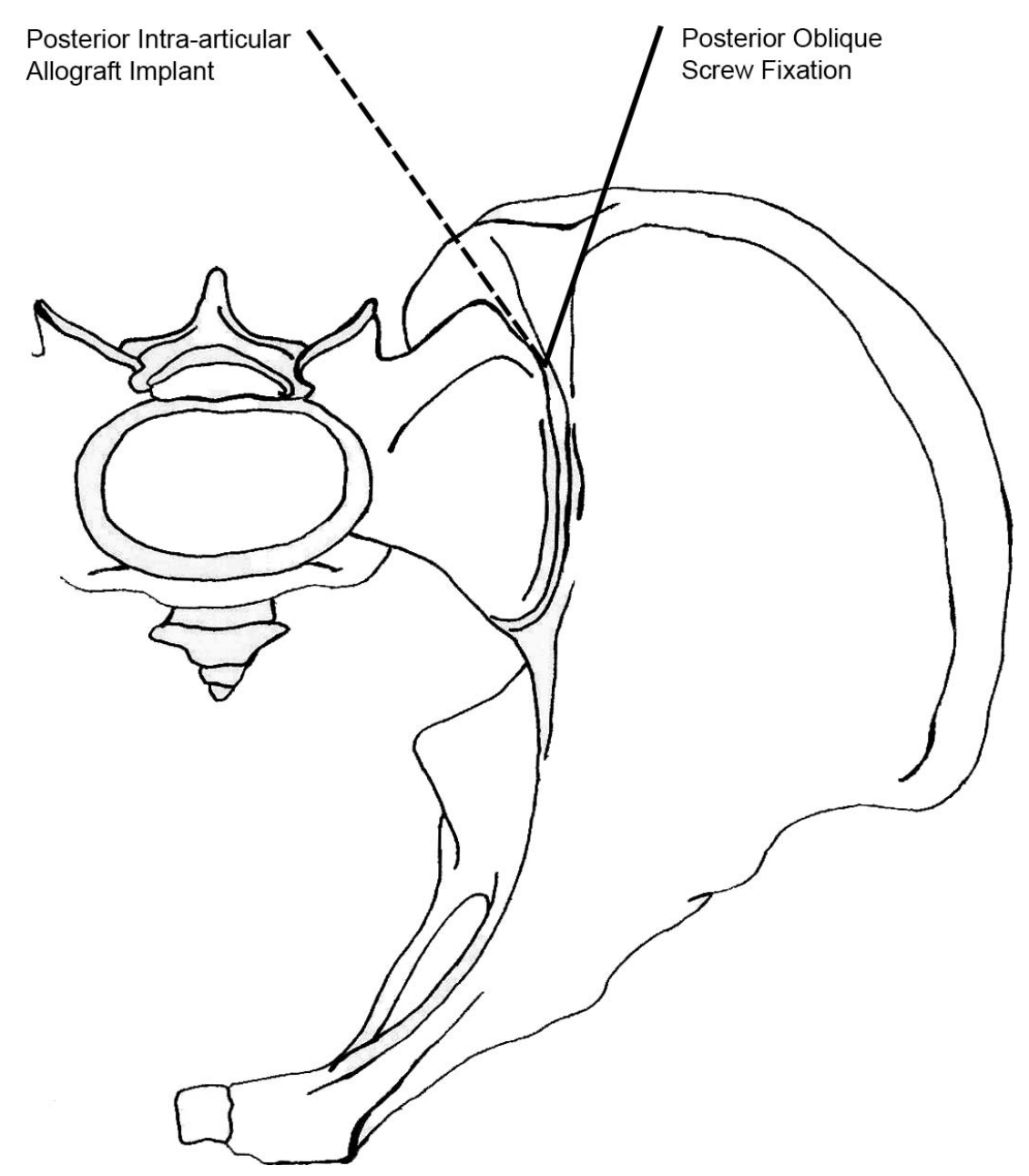

Figure 1. Axial view of posterior sacroiliac joint fusion trajectory. Illustration used with permission from Min A. Lee.

Mean Oswestry disability index (ODI) score decreased from 64.1 at baseline to 57 at follow-up. Successful sacroiliac fusion, defined as lack of loosening around the implants and bone bridging across the joint, was seen in $79 \%$ of joints.

A level-II prospective observational study reported on 171 patients who similarly underwent sacroiliac arthrodesis using the same hollow threaded fusion cage (DIANA cage, Signus). ${ }^{21}$ The study involved 20 hospitals in Germany. The ODI improved from 51 to 33, the Short FormMcGill Pain Questionnaire (MPQ) scores decreased from $50 \%$ to $31 \%$, the Short Form- 12 physical component summary rose from $22 \%$ to $41 \%$, the mental component summary increased from $40 \%$ to $55 \%$, and pain as measured by the VAS decreased from 74 to 37 points. In the follow-up computed tomography (CT) scans $31 \%$ of the patients showed SIJ fusion, which is a lower rate compared with some of the other approaches used to fuse the joint. The authors address this concerning finding, attributing the low percentage of radiographic fusion on the early postoperative stage (6 months) at which patients received CT scans, inadequate preparation of the recess or deposit of bone (substitute) material, poor positioning of the implant, and severe osteoporosis. There were no data on length of hospital stay included in this particular study.

Wise and Dall ${ }^{20}$ published a prospective study on 13 consecutive patients who underwent minimally invasive SIJ fusion using threaded fusion cages filled with recombinant human bone morphogenetic protein-2. The mean follow-up period was 29.5 months (range, 24-35 months). Significant improvements were seen in the final low back pain score on a VAS, with an average improvement of 4.9. Leg pain improved an average of 2.4 points, and dyspareunia pain improved an average of 2.6 points. The mean estimated blood loss was less than $100 \mathrm{~mL}$; there were no infections or neurovascular complications. The overall fusion rate was $89 \%$ (17 of 19 joints) as assessed by postoperative CT scan obtained 6 


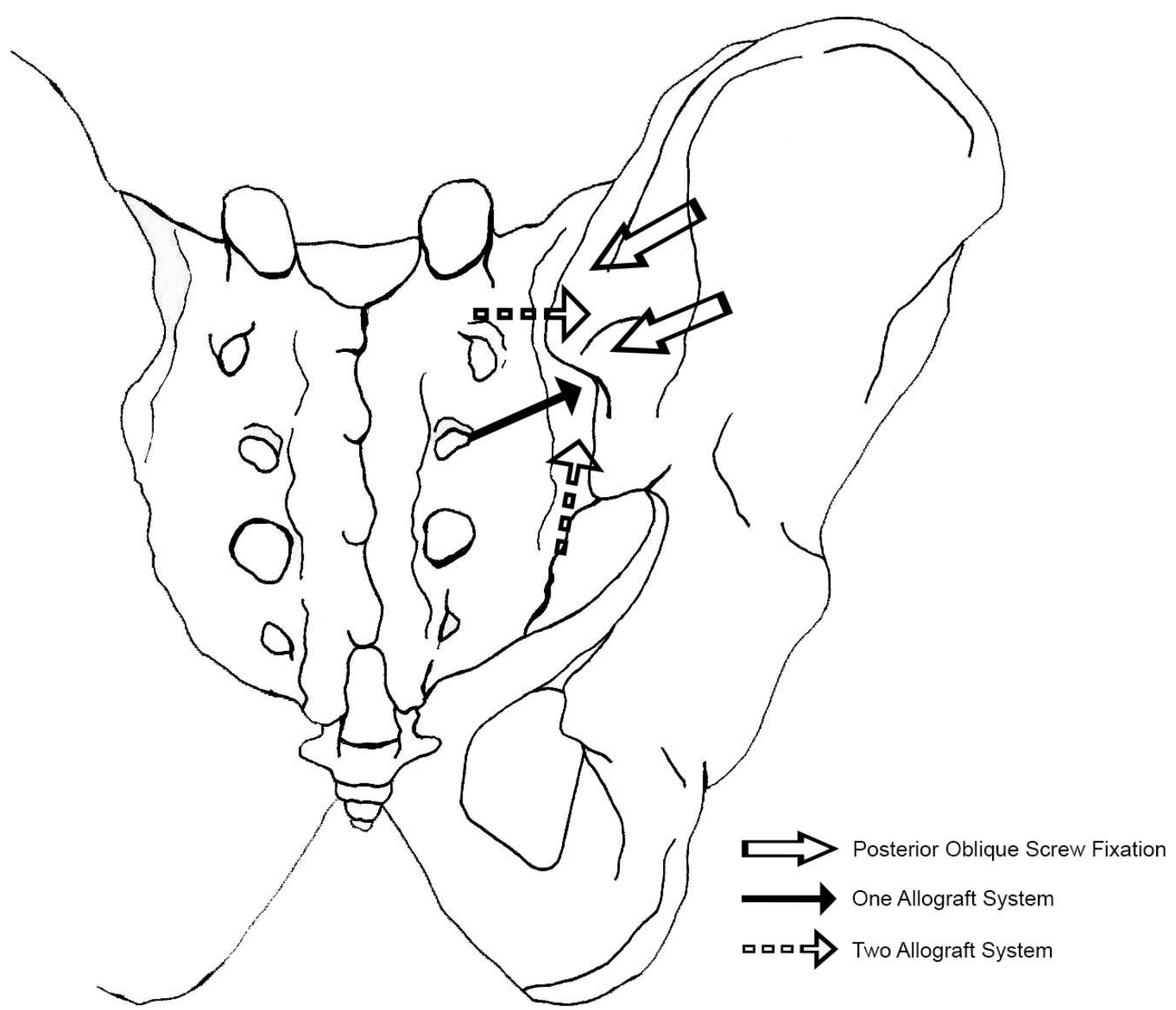

Figure 2. Posterior-anterior view of sacroiliac joint fusion trajectory. Illustration used with permission from Min A. Lee.

months after the procedure. The only complication was 1 revision to an open arthrodesis secondary to nonunion and persistent pain.

In a retrospective case series by Rajpal and Burneikiene. $^{22} 24$ patients underwent a unilateral (22) or bilateral (2) SIJ fusion utilizing the posterior oblique approach with cylindrical threaded implants (Medtronic, Minneapolis, Minnesota). A statistically significant reduction $(P=.0028)$ in low back pain scores was noted from an average baseline score of $6.6 \pm 2.4$ to $3.7 \pm 3.3$ postoperatively. Leg pain scores decreased from $4.8 \pm 3.8$ to $1.5 \pm 2.9(P=$ $.0034)$. Mean total satisfaction score was $89.0 \% \pm$ $27.6 \%$.

The remaining 5 case series describe a novel and less invasive posterior approach, which involves inserting an allograft directly into the joint space. This technique is similar to that of the previously discussed DIANA cage, as it does not attempt to cross the SIJ, but rather provides an interference fit within the joint.
Patterson et $\mathrm{al}^{23}$ and Mann et $\mathrm{al}^{24}$ both reported on retrospective studies with 21 and 10 patients, respectively.' These studies utilized a novel SI fusion system consisting of 2 specialized cortical structural allografts and 2 cancellous DBM human allografts (CornerLoc, Tulsa, Oklahoma) to transfix the SIJ. In the Patterson et $\mathrm{al}^{23}$ study there was a reported $73.2 \%$ average pain reduction at $10-12$ weeks, for an average of 6.29 reduction in NRS. At least $60 \%$ reduction in overall pain was reported by $81.8 \%$ of patients. Overall satisfaction with the procedure was reportedly an average of 4.95 ( $0-5$ scale). Mann et $\mathrm{al}^{24}$ similarly recorded reduction of NRS and average percentages of improvement at 12 weeks but also extended the retrospective analysis to 12 months. At 12 weeks, the average NRS reduction was 4.6 with a $62.3 \%$ average pain reduction. At 12 months there were substantial improvements compared both to preoperative and 12-week scores; the average NRS reduction was 6.1 with a $79.2 \%$ average pain reduction. 


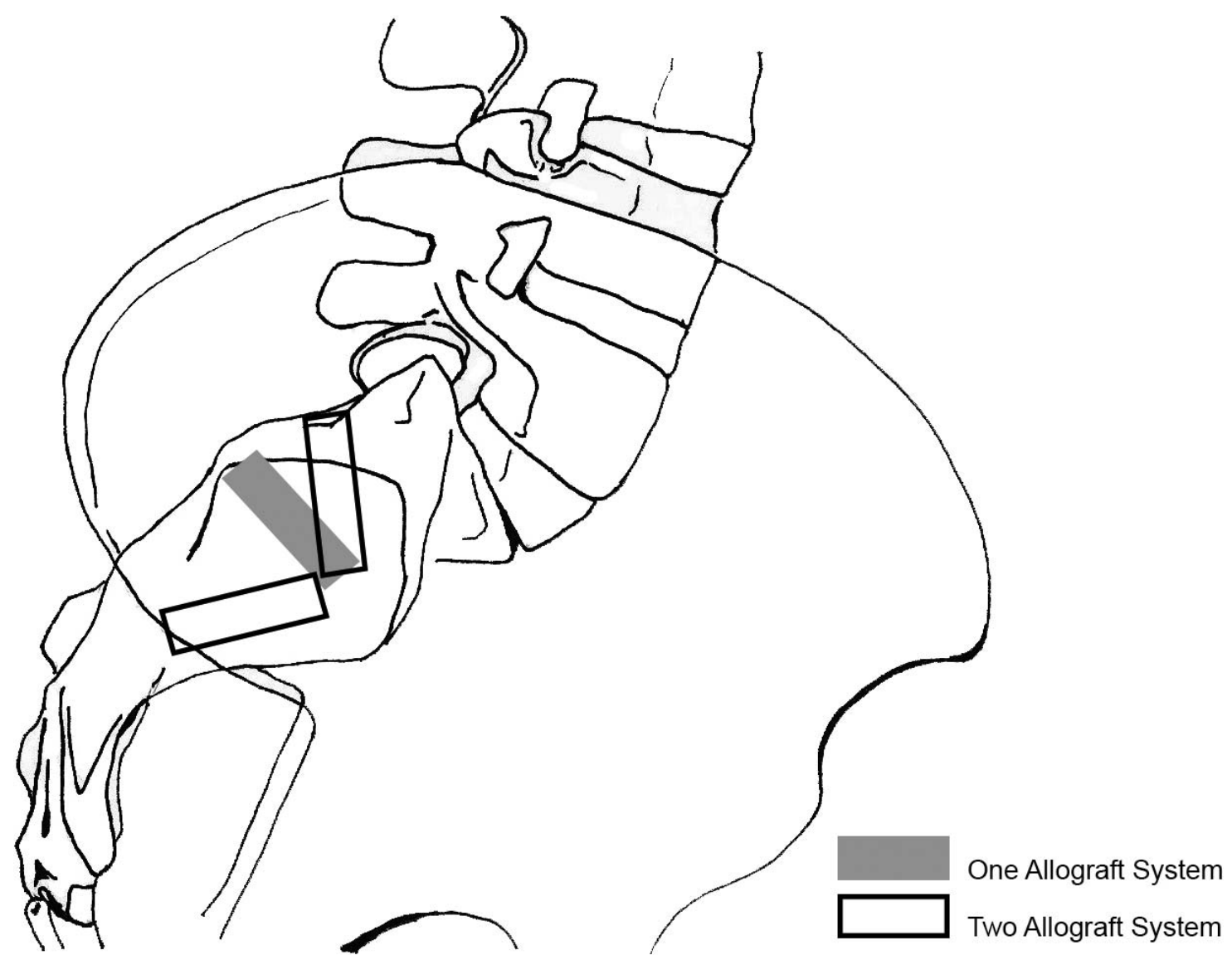

Figure 3. Lateral view of sacroiliac joint fusion allograft placement. Illustration used with permission from Min A. Lee.

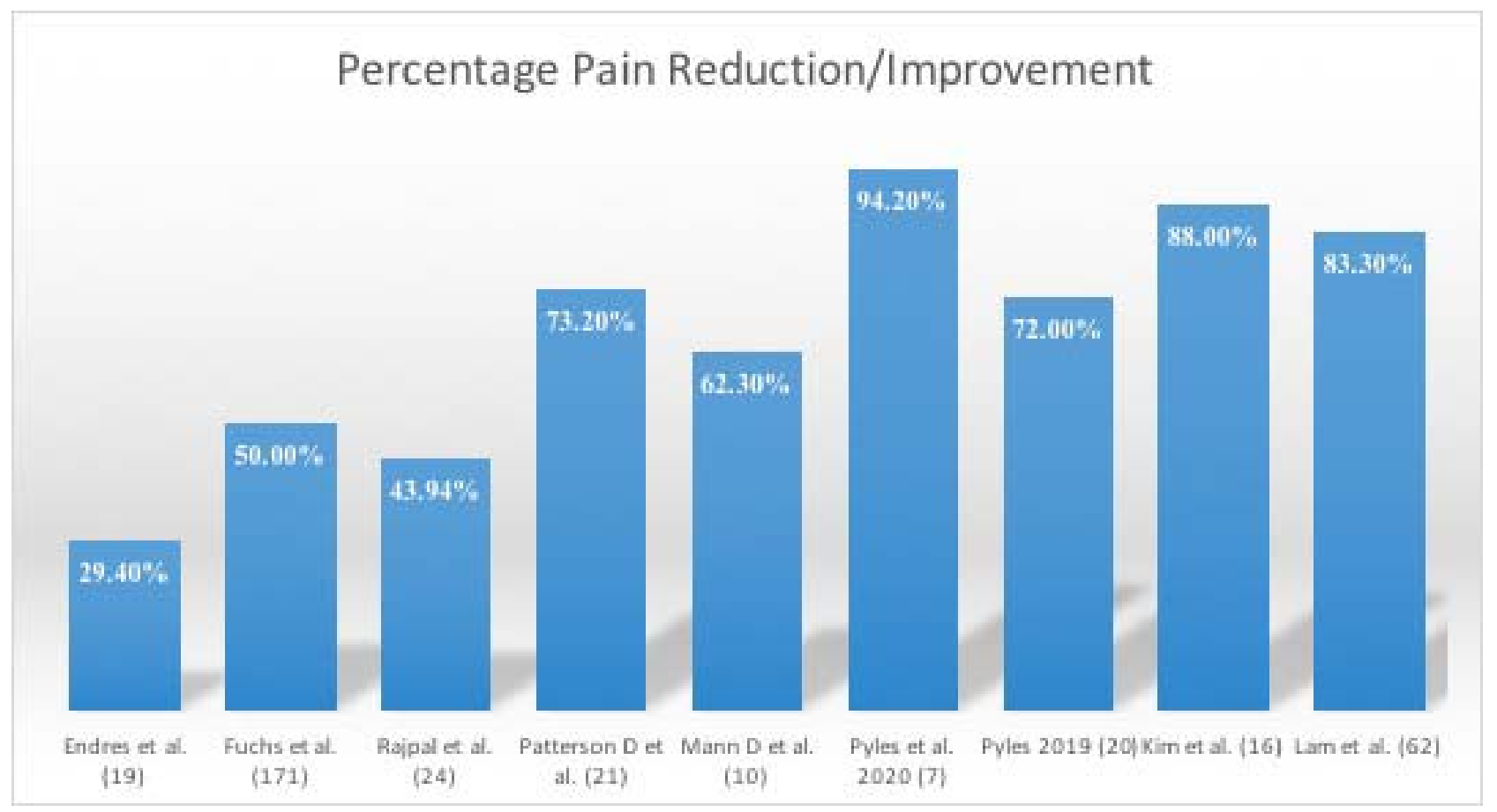

Figure 4. Individual studies and weighted average percentage pain reduction/improvement. Number of participants in study designated in parentheses. 


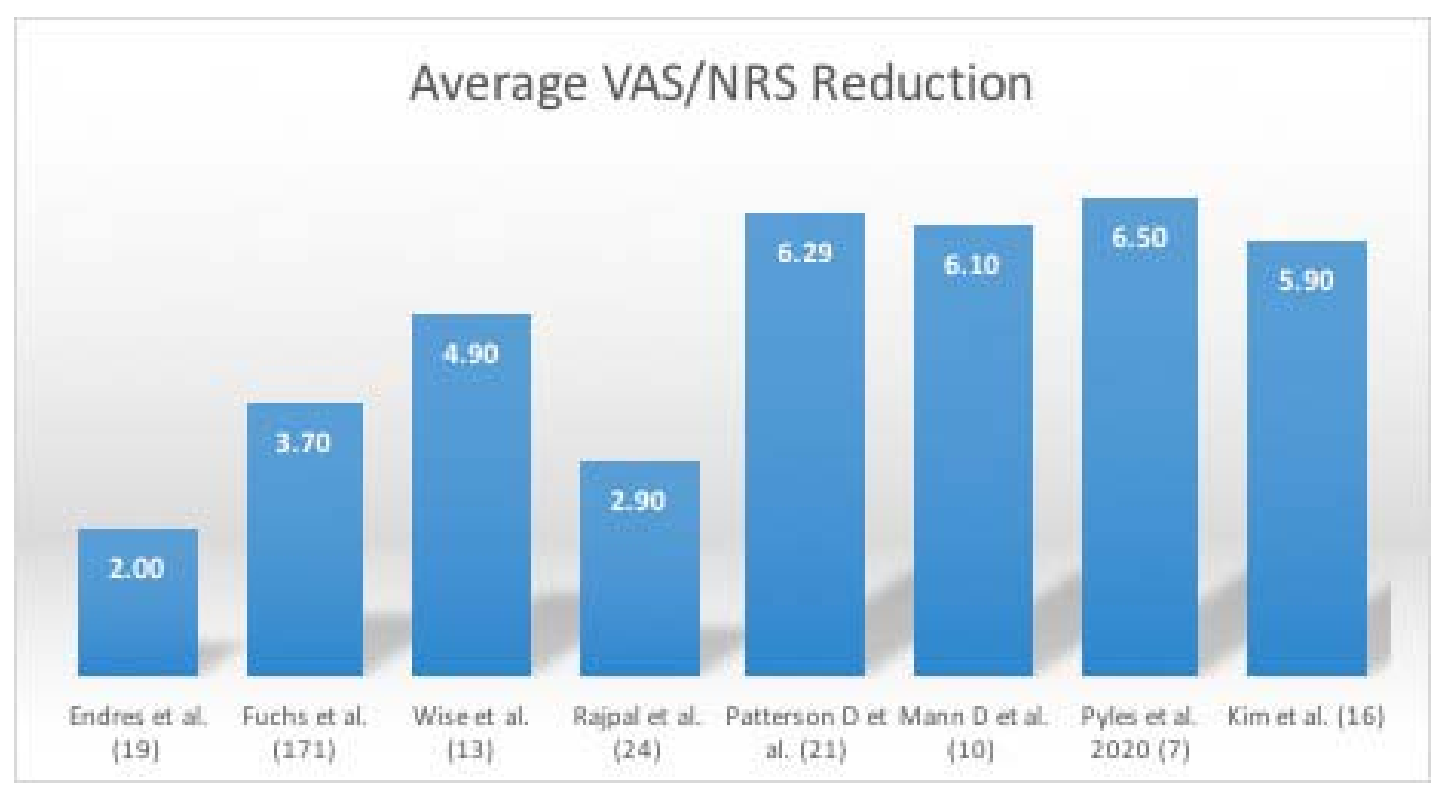

Figure 5. Individual studies and weighted average VAS/NRS reduction. Number of participants in study designated in parentheses. VAS indicates visual analog scale; NRS, numerical rating scale.

In case series by Pyles et al, ${ }^{25}$ Pyles, ${ }^{26}$ and Kim et $\mathrm{al}^{27}$ a novel fusion system consisting of a single ridged allograft with DBM-filled window (PainTEQ, Tampa, Florida) was utilized. In the Pyles et $\mathrm{al}^{25}$ case series 7 patients were followed for 5.1 months. Average NRS reduction was 6.5 with a $94.2 \%$ pain reduction at follow-up. The second case series by Pyles ${ }^{26}$ followed 20 patients with 55\% (11 patients) having complete resolution of pain, with average $72 \%$ pain reduction at 6 months. Kim et $\mathrm{al}^{27}$ reported on a case series of 16 patients, with a mean decrease of 5.9 in NRS with paired $t$ value of $-11.3243(P<.00001)$, for an $88 \%$ pain reduction.

A multicenter retrospective chart review case series evaluated the 3-month outcomes and safety utilizing a posterior approach, minimally invasive SIJ fusion (PainTEQ). In total, 62 patients were included in the study results. The average percentage of relief at first follow-up was reported to be $78.6 \%$ and percentage of relief at 3-month followup was $83.3 \%$. Forty-five patients reported their medication use habits around the time of implant. Twelve out of the 45 patients $(26.7 \%)$ reported decreased opioid use. Eleven patients in total specified the milligram morphine equivalents (MMEs) used pre- and postimplant. Of these 11 patients, 5 reported decreased medication use with an average of $75.0 \%$ MME reduction. Three patients $(4.35 \%)$ report no relief at 3 months while 30 patients $(43.5 \%)$ reported near complete resolu- tion of their prior pain. No device-related adverse events were reported $(0 \%){ }^{28}$

Nonunion was the most common complication noted, but was tracked in only 2 of the studies included utilizing postprocedure imaging. This is a limitation of the more novel posterior SIJ fusion systems discussed above, which have preliminary evidence supporting improvement in pain measures and stabilization but have not been yet been correlated with imaging studies.

Fuchs and Ruhl ${ }^{21}$ found that on follow-up CT scans $31 \%$ of the patients showed SIJ fusion, which is a lower rate than expected and lower when compared with some of the other approaches. Surprisingly, there was no statistically significant correlation between the clinical findings and fusion rates. The study reported ODI improved from 51 to 33, the Short Form-McGill Pain Questionnaire (MPQ) scores decreased from $50 \%$ to $31 \%$, the Short Form-12 physical component summary rose from $22 \%$ to $41 \%$, the mental component summary increased from $40 \%$ to $55 \%$, and pain as measured by the VAS decreased from 74 to 37 points $(50 \%$ pain reduction). Only 1 patient was taken back for open revision arthrodesis due to lack of fusion (Wise and Dall $^{20}$ ). Rajpal and Burneikiene ${ }^{22}$ reported 2 patients who had symptomatic subcutaneous hematomas, which resolved spontaneously, and 2 patients who had superficial wound infections, which resolved after being treated with antibiotics. One patient developed an osteophyte on the lateral 
aspect of the implant which required local osteophytectomy, with an improvement in patient symptoms. No other hardware or revision surgeries were required. Remaining studies reported no serious adverse events.

\section{DISCUSSION}

The SIJ as a pain source has historically been a point of debate for many clinicians. Although it was recognized as early as 1905 by Goldwaite and Osgood, ${ }^{29}$ it was not until the validation of SIJ maneuvers that SIJ dysfunction gained wider acceptance. $^{30}$ Despite the identification of these various SIJ pain provocation maneuvers, these maneuvers do not have a high positive predictive value. $^{31,32}$ Diagnostic imaging, including CT scans, magnetic resonance imaging, and radiographs, may be used to rule out other sources of low back pain. Overall, diagnostic SIJ injections with image guidance remain the gold standard.

With increased recognition of the SIJ as a pain source, treatments have been historically nonsurgical in nature. Common treatments included bracing, medications, activity modification, manual therapy, chiropractic manipulation, physical therapy, and intra-articular SIJ injections. ${ }^{33}$ Even with these treatments, there remained recalcitrant cases where symptoms were not alleviated or only temporarily alleviated. These treatments did fill a void since patients previously were not being offered more advanced treatments. Today, these recalcitrant cases are being considered for a posterior sacroiliac ablation and/or a SIJ fusion.

Both SIJ ablation and fusion have been shown to be effective. In a recent systematic review, both treatments reported mean improvements in pain and functional outcome. ${ }^{34}$ In a large retrospective study over 72 months, patients treated with continued conservative management had no longterm improvement in pain or disability, increased their use of opioids, and had poor long-term work status. Sacroiliac denervation patients had intermediate responses. SIJ fusion patients had large improvements in SIJ pain (mean VAS change of 6 points), large improvements in disability (mean ODI change of 25 points), a decrease in opioid use, and good final work status. ${ }^{35}$

SIJ arthrodesis was originally performed as an open procedure and used sparingly due to the lack of recognition of the SIJ as a pain generator as well as the invasive nature of the procedure itself. In the past couple of decades, the use of a minimally invasive transiliac approach became recognized with multiple high-level studies being published..$^{10-18}$ The use of a minimally invasive posterior approach has been more recently been proposed as a less invasive and hypothetically safer approach. Specifically, one is able to avoid the neurovascular bundle that is often associated with the transiliac approach. ${ }^{36,37}$ For these very reasons, the authors focused specifically on the posterior and posterior lateral oblique minimally invasive SIJ fusion approaches.

Despite the fact that the studies included in this review are mainly level IV studies, the numbers show preliminary evidence of substantial improvements in the outcome measures of pain reduction, percentage of pain improvement, functional improvement, medication reduction, overall patient satisfaction, as well as low complication rates. This implies that the posterior fusion approach may be a consideration in the treatment of recalcitrant SIJ pain.

Newer systems now allow for stabilization and/or fusion by placing an allograft implant within the joint. This is not a new concept as seen in a previous study by McGuire et al. ${ }^{38}$ Cranial and caudal fibular dowel grafts, harvested from the posterosuperior iliac spine, were shown to be effective in successful fusion of the SIJ. Fusion was deemed to be present when bone-bridging trabeculae could be seen crossing the SIJ on either oblique x-rays or by CT scan. Thirty-four patients $(N=37)$ with SIJ arthrodesis $(89.5 \%)$ healed and led to substantial improvement in VAS pain scores (preoperative 9.1, postoperative $3.4 ; P<.001)$. The newer posterior systems include a cortical allograft and therefore harvesting of bone is not required. Further distinguishing them is that the procedure is performed percutaneously. These systems allow for an outpatient-based procedure and therefore do not require weight-bearing restrictions of their other sacroiliac fusion system counterparts.

The authors recognize that there is a considerable need for further research into posterior SIJ fusion systems as a whole. The authors recommend judicious use of these devices and scrupulous patient selection until further evidence is available. A randomized controlled trial to study the outcomes of minimally invasive transiliac sacroiliac fusion versus posterior/posterior-lateral joint fusion would be a logical step in validating this preliminary data. 
There has been a recently published SIJ dysfunction algorithm ${ }^{39}$ which includes minimally-invasive sacroiliac fusion. Future publications on novel minimally invasive posterior sacroiliac fusion systems include forthcoming biomechanical studies, and 2 ongoing industry-sponsored multi-centered studies with 12-month follow-up.

\section{CONCLUSION}

SIJ dysfunction accounts for a substantial amount of reported lower back pain. Surgical stabilization and/or fusion of the SIJ may be considered when a patient has persistent moderate to severe pain, functional impairment, and failed intensive nonoperative care. While the lateral or transiliac approach has been well published, the posterior and posterior oblique approach has been recently introduced as an alternative means of stabilization of the SIJ. Preliminary case series presented reveal consistent decreases in pain scores and low complication rates. Formal meta-analysis was not possible given the preliminary data; however, it will be imperative as further studies begin to emerge on this developing therapy.

\section{REFERENCES}

1. Dahlhamer J, Lucas J, Zelaya C, et al. Prevalence of chronic pain and high-impact chronic pain among adultsUnited States, 2016. Morbid Mortal Weekly Rep. 2018;67(36):1001-1006.

2. Institute of Medicine. Relieving pain in America: a blueprint for transforming prevention, care, education, and research. Washington, DC: National Academies Press; 2011.

3. March L, Smith EUR, Hoy DG, et al. Burden of disability due to musculoskeletal (MSK) disorders. Best Pract Res Clin Rheumatol. 2014;28(3):353-366. doi:10.1016/j.berh.2014.08.002

4. Yoshihara H. Sacroiliac joint pain after lumbar/lumbosacral fusion: current knowledge. Eur Spine J. 2012;21(9):17881796.

5. Guentchev M, Preuss C, Rink R, Peter L, Wocker E-L, Tuettenberg J. Technical note: treatment of sacroiliac joint pain with peripheral nerve stimulation. Neuromodulation Technol Neural Interface. 2015;18(5):392-396. http://doi.wiley.com/10. 1111/ner.12255

6. Cher D, Polly D, Berven S. Sacroiliac joint pain: burden of disease. Med Devices Evid Res. 2014;7(1):73-81.

7. Tsoi C, Griffith JF, Lee RKL, Wong PCH, Tam LS. Imaging of sacroiliitis: current status, limitations and pitfalls. Quant Imaging Med Surg. 2019;9(2):318-335.

8. Polly DW, Swofford J, Whang PG, et al. Two-year outcomes from a randomized controlled trial of minimally invasive sacroiliac joint fusion vs. non-surgical management for sacroiliac joint dysfunction. Int J Spine Surg. 2016;10:28.

9. Buchowski JM, Kebaish KM, Sinkov V, Cohen DB, Sieber AN, Kostuik JP. Functional and radiographic outcome of sacroiliac arthrodesis for the disorders of the sacroiliac joint. Spine J. 2005;5:520-528.

10. Dengler J, Kools D, Pflugmacher R, et al.. Randomized trial of sacroiliac joint arthrodesis compared with conservative management for chronic low back pain attributed to the sacroiliac joint. J Bone Joint Surg. 2019;101(5):400-411.

11. Sturesson B, Kools D, Pflugmacher R, Gasbarrini A, Prestamburgo D, Dengler J. Six-month outcomes from a randomized controlled trial of minimally invasive SI joint fusion with triangular titanium implants vs conservative management. Eur Spine J. 2017;26(3):708-719.

12. Dhon BS, Bitan F, Lockstadt H, et al. Triangular titanium implants for minimally invasive sacroiliac joint fusion: 2-year follow-up from a prospective multicenter trial. Int $J$ Spine Surg. 2016;10:13.

13. Rudolf L. Sacroiliac joint arthrodesis-MIS technique with titanium implants: report of the first 50 patients and outcomes. Open Orthop J. 2012;6:495-502.

14. Cummings J Jr, Capobianco RA. Minimally invasive sacroiliac joint fusion: one-year outcomes in 18 patients. Ann Surg Innov Res. 2013;7(1):12.

15. Sachs D, Capobianco R, Cher D, et al. One-year outcomes after minimally invasive sacroiliac joint fusion with a series of triangular implants: a multicenter, patient-level analysis. Med Devices (Auckl). 2014;7:299-304.

16. Smith AG, Capobianco R, Cher D, et al. Open versus minimally invasive sacroiliac joint fusion: a multi-center comparison of perioperative measures and clinical outcomes. Ann Surg Innov Res. 2013;7(1):14.

17. Vanaclocha V, Herrera JM, Sáiz-Sapena N, Rivera-Paz M, Verdú-López F. Minimally invasive sacroiliac joint fusion, radiofrequency denervation, and conservative management for sacroiliac joint pain: 6-year comparative case series. Neurosurgery. 2018;82(1):48-55.

18. Dengler JD, Kools D, Pflugmacher R, et al. 1-year results of a randomized controlled trial of conservative management vs. minimally invasive surgical Treatment for sacroiliac joint pain. Pain Physician. 2017;20(6):537-550.

19. Endres S, Ludwig E. Outcome of distraction interference arthrodesis of the sacroiliac joint for sacroiliac arthritis. Indian J Orthop. 2013;47(5):437-442.

20. Wise CL, Dall BE. Minimally invasive sacroiliac arthrodesis: outcomes of a new technique. J Spinal Disord Tech. 2008;21(8):579-584.

21. Fuchs V, Ruhl B. Distraction arthrodesis of the sacroiliac joint: 2-year results of a descriptive prospective multi-center cohort study in 171 patients. Eur Spine J. 2018;27(1):194-204.

22. Rajpal S, Burneikiene S. Minimally invasive sacroiliac joint fusion with cylindrical threaded implants using intraoperative stereotactic navigation. World Neurosurg. 2019;122:e1588-e1591. doi:10.1016/j.wneu.2018.11.116

23. Patterson D, Wilits M, Fiks V, et al. Pain reduction and functional improvement after posterior approach SI stabilization and fusion with specialized graft: a case series. Paper presented at: CASIPP Annual Meeting 2018.

24. Mann D, Willits M, Fiks V, et al. Pain reduction at 12 months after posterior approach SI stabilization and fusion with specialized graft: 10 case series. Paper presented at: ASPN Annual Meeting 2019.

25. Pyles S, Ortiz A, Lam C, et al. 2020. LINQ SI Fusion for 
pain relief in SCS patient: a case series. Paper presented at: NANS Annual Meeting 2020.

26. Pyles S. Sacroiliac LINQ fusion: 20 patient case series. Paper presented at: FSIPP Annual Meeting 2019.

27. Kim D, Sayed D, Lam C, et al. Initial experience with MI SI fusion device; a retrospective case series. Paper presented at: ASRA Annual Meeting 2019.

28. Lam CM, Pyles S, Balter K, Sayed D. Multicenter outcomes in minimally invasive sacroiliac fusion. Paper presented at: ASIPP Annual Meeting 2020.

29. Goldthwait JE, Osgood RB. A consideration of the pelvic articulations from an anatomical, pathological and clinical standpoint. Boston Med Surg J. 1905;152:593-601.

30. Laslett M, Williams M. The reliability of selected pain provocation tests for sacroiliac joint pathology. Spine (Phila Pa 1976). 1994;19(11):1243-1249. doi: 10.1097/00007632199405310-00009

31. Laslett M, Aprill CN, McDonald B, Young SB. Diagnosis of sacroiliac joint pain: validity of individual provocation tests and composites of tests. Manual Ther. 2005;10:207-218.

32. Dreyfuss P, Michaelsen M, Pauza K, McLarty J, Bogduk $\mathrm{N}$. The value of medical history and physical examination in diagnosing sacroiliac joint pain. Spine. 1996;21:2594-2602.

33. Hansen H, Manchikanti L, Simopoulos TT, et al. A systematic evaluation of the therapeutic effectiveness of sacroiliac joint interventions. Pain Physician. 2012;15:E247E278.

34. Ashman B, Norvell DC, Hermsmeyer JT. Chronic sacroiliac joint pain: fusion versus denervation as treatment options. Evid Based Spine Care J. 2010;1(3):35-44. doi:10.1055/ s-0030-1267066

35. Vanaclocha V, Herrera JM, Sáiz-Sapena N, Rivera-Paz M, Verdú-López F. Minimally invasive sacroiliac joint fusion, radiofrequency denervation, and conservative management for sacroiliac joint pain: 6-year comparative case series. Neurosurgery, 2018;82(1):48-55. doi:10.1093/neuros/nyx185

36. Collinge C, Coons D, Aschenbrenner J. Risks to the superior gluteal neurovascular bundle during percutaneous iliosacral screw insertion: an anatomical cadaver study. $J$ Orthop Trauma. 2005;19(2):96-101. doi:10.1097/00005131200502000-00005
37. Maled I, Velez R, Lopez R, Batalla L, Caja VL. Pseudoaneurysm of the superior gluteal artery during iliosacral screw fixation. Acta Orthop Belg. 2007;73(4):544-547.

38. McGuire RA, Chen Z, Donahoe K. Dual fibular allograft dowel technique for sacroiliac joint arthrodesis. Evid Based Spine Care J. 2012;3(3):21-28. doi:10.1055/s-00321327806

39. Falowski S, Sayed D, Pope J, et al. A review and algorithm in the diagnosis and treatment of sacroiliac joint pain. J Pain Res. 2020;13:3337-3348. doi:10.2147/JPR.S279390

Disclosures and COI: Dr David Lee reports being a speaker for Abbott Neuromodulation. Dr Denis G. Patterson reports being a consultant for Abbott, CornerLoc, Flowonix, Saluda, Vertos; being a participant of speakers bureau for Abbott, Allergan, Amgen, Cornerloc, Flowonix, Lundbeck, and Vertos; an administrative board member for AIS, CornerLoc, Saluda, Spark Biomedical; and researcher for Abbott, Flowonix, Nevro. Dr Dawood Sayed reports being a consultant and speaker for Abbott, Boston Scientific, Flowonix, Medtronic, Nevro, PainTEQ, SPR Therapeutics, Vertos, and Vertiflex.

Corresponding Author: David W. Lee, MD, 680 Langsdorf Dr, Ste 103, Fullerton, CA 92831. Phone: (714) 879-0050; Fax: (714) 879-0249; Email: lee.davidw@gmail.com.

Published 1 June 2021

This manuscript is generously published free of charge by ISASS, the International Society for the Advancement of Spine Surgery. Copyright $\odot 2021$ ISASS. To see more or order reprints or permissions, see http://ijssurgery.com. 